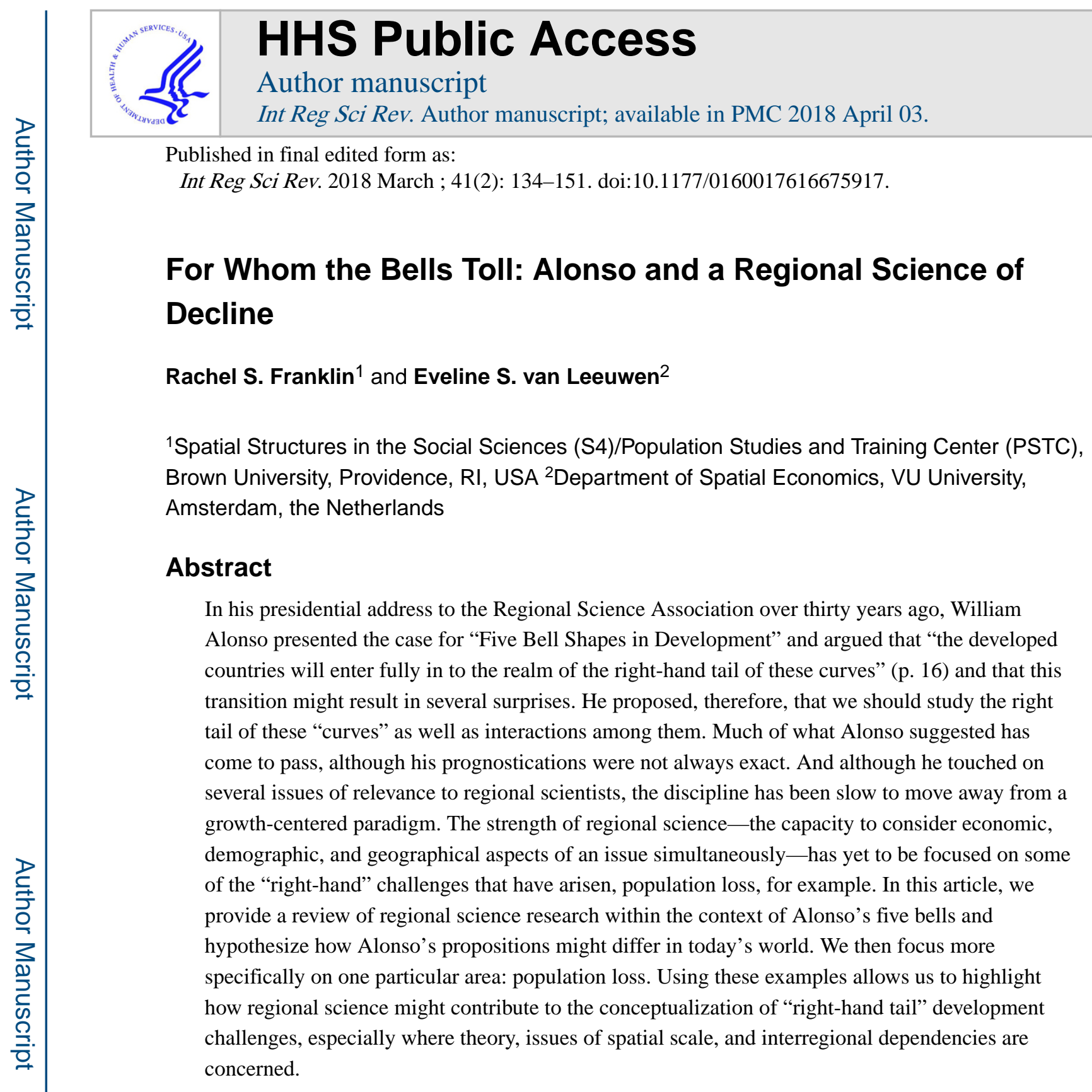

\title{
Keywords
}

regional science; population decline; spatial inequality

\footnotetext{
Reprints and permission: sagepub.com/journalsPermissions.nav

Corresponding Author: Rachel S. Franklin, Spatial Structures in the Social Sciences (S4)/Population Studies and Training Center (PSTC), Brown University, 108 George St., Box 1916, Maxcy Hall, Providence, RI 02912, USA. rachel_franklin@ brown.edu. Authors' Note

The content is solely the responsibility of the authors and does not necessarily represent the official views of the National Institutes of Health.

Declaration of Conflicting Interests

The author(s) declared no potential conflicts of interest with respect to the research, authorship, and/or publication of this article.
} 


\section{Introduction: What Goes Up Must Come Down}

It is a basic rule of life encountered by most children at an early age: what goes up must come down. Gravity may be defied, but only temporarily, before physical laws prevail. Fundamental laws are more difficult to establish where the social or economic world is concerned, and social scientists have expended decades' worth of research effort in attempting to lay out inviolable rules that govern aspects of human behavior. In the social sciences in general - and regional science is certainly no exception-attention has tended to focus on aspects of growth or equilibrium, whether related to population, economies, governments, or human behavior. When lack of growth is examined, it is generally within a larger context of explaining why deviations occur and what-especially where economic or social disparities are concerned — can be done to ameliorate them. So, for example, literature on determinants of economic growth, regional economic convergence, core-periphery disparities, and urbanization abounds in regional science. Even subfields such as spatial optimization or retail geography tend to focus on best locations for new facilities or maximizing coverage within a context of population growth. But what if lack of growth or even decline were to become the new "normal?"

In 1937—almost eighty years ago-Keynes highlighted the inability of humankind to deal with decline. "The future never resembles the past." Nevertheless, we as stakeholders, policy makers, or researchers tend to "assume that the future will resemble the past." Even when economic or population decline is apparent "most of us offer a great resistance to acting on it in practice" (Keynes 1937, 13). In fact, many theories subscribe to the notion that rapid growth cannot be sustained indefinitely. This holds for products, as explained in the productlife-cycle theory as well as for countries (Rostow 1959). Even though stages of rapid (economic) growth are known to be temporal, and are likely to be followed by moderate growth and possibly even decline, this is generally seen as inappropriate and rejected by both politicians and researchers. From this perspective, the future does resemble the past: in spite of economic recessions between 2008 and 2013 and population decline taking place in many regions in the world, by far the majority of academic and policy publications focus on and assume growth.

Within our own discipline, an exhortation for regional scientists to devote attention to the alternatives to growth goes back at least as far as 1980 and William Alonso's presidential address to the Regional Science Association (1980). In his address, Alonso outlines five basic principles-the rise and fall of (1) economic growth, (2) social inequality, (3) regional inequality, (4) geographic concentration, and (5) the demographic transition-that have guided social scientists' engagement with the world around them. In spite of his persuasive argument that social and regional scientists should consider postgrowth scenarios or even paradigms, in general Alonso's call has gone unheeded. This is unfortunate. In this article, we suggest that, even in cases in which Alonso's conclusions proved shortsighted (e.g., the temporary nature of the counterurbanization phenomenon of the 1970s or the nonmaterialization of the equalizing effects of the regional economic convergence process implied by traditional economic growth models), his underlying rationale was solid. We argue that the timing is now right for regional scientists to reengage with Alonso's proposal that we devote research energy to the "right side" or inverse of the five growth-oriented 
curves discussed in his article and that impending population loss occurring in many areas of the developed world offers a forcible incentive to do so.

This article makes two propositions. The first is that the world is changing and growth or expansion, whether economic or demographic, should no longer serve as the sole paradigmatic guiding light. Inequality, decline, equilibrium, or stagnation may in fact be the new reality. Perhaps lagging regions will never catch up to their peers. More dramatically, perhaps any regional convergence that has been achieved is only temporary and anomalous, and the real equilibrium is one of disparity. If this is the case, research and policy development should be palliative: less about encouraging uniformity and more about helping unfortunate areas, regions, and people to achieve and maintain a certain quality of life (i.e., Blank 2005).

The second proposition is that population decline epitomizes the sorts of topics to which Alonso was referring in his address: not only the relevance of each of his five bells for the subject but also the interactions across bells that must be considered in order for theory, models, and policy to be developed. Population decline sits at a regional science crossroads: it is spatial, demographic, and economic at once. Nevertheless, it is an understudied topic in regional science, but one that is, nonetheless, here to stay, and that would benefit from the expertise that regional scientists converted to Alonso's views could bring to the subject. ${ }^{1}$ Building understanding of the myriad aspects of decline requires researchers positioned to wrangle with social, geographic, demographic, and economic components-all at once. This is a strength of regional science.

Thus, the goals of this article are twofold. First, we aim to reintroduce Alonso's argument that the right-hand side of his five curves matters and that we in regional science have constrained ourselves overlong to the left-hand case (something like perpetual growth). Second, we seek to provide some ideas of what right-side regional science might look likeand we accomplish this through the important case study of population decline. The order of the article is as follows. In the second section, we provide a brief recapitulation of Alonso's five bells, emphasizing those aspects most relevant to regional scientists. The subsequent section covers the extent to which Alonso's prognostications have played out and how regional science has contributed knowledge to each area of research. Fourth and fifth sections are the crux of the article: here we imagine what right-side regional science might look like and opine on the theory, expertise, and topical insight such a perspective might generate. We then focus more specifically on the subject of population decline, with the aim of offering a firm example of the utility of Alonso's views as well as to build interest within the field of regional science in the study of decline. In the sixth section, we offer conclusions and suggestions for future research.

\footnotetext{
${ }^{1}$ Demography, of course, underpins every aspect of regional science. It is either the subject of direct study, as in the case of migration, human capital, or urbanization, or it is one key element that plays a role in some larger system or process.
} 


\section{Alonso's Five Bells}

In his presidential address, Alonso (1980) collapses the development process into five interrelated bells or curves. Neither the assumption of a bell shape nor the description itself is meant to be taken as a rule or law. Rather, Alonso posits them as "heuristics" or guiding principles that help shed light on particular aspects of development. By focusing on Alonso's approach to integrating social and economic theories, we do not imply that his is the only or even, necessarily, the best perspective. And certainly regional science is not the sole discipline capable of such an exercise. Arguably, new insights can be generated through any effort at deconstruct-ing and then reassembling established theories or worldviews. Alonso's address still resonates, however, especially for those researchers interested in the spatial or regional aspects of development.

By Alonso's reckoning, the five bell-shaped processes in development are (1) the stages of economic development, (2) social inequality, (3) regional inequality, (4) geographic concentration, and (5) the demographic transition. The first process, development itself, simply characterizes the pace at which development occurs: a rapid pace that, at some point, slows. This simple proposition suggests in some way the remaining four. As a country or region moves through the stages of development, social inequality increases within an area across different socioeconomic dimensions such as race, class, or occupation. At some point, increases in social inequality slow or even decrease as the fruits of economic development diffuse from a relatively small group to the larger. This is the well-known Kuznets relationship between economic growth and inequality. This relationship carries the implication that temporary increases in inequality that occur with growth are justifiable, given the longer-term expectation that inequality eventually decreases after a certain level of development (Kuznets 1955).

Concurrently, according to Alonso, development leads to increased spatial inequality in levels of development across regions. Some areas grow and some lag behind, with the result that the benefits of economic growth are not only distributed unequally across groups but also across regions. This too is expected to be temporary: after a certain level of development is attained, interregional movements of labor and capital should see development begin to level out across regions. The fourth proposition, geographic concentration, will also be familiar to regional scientists. Original locations of economic activity will draw in further resources and people, leading to concentrations of firms, people, and activity in general. Again, after some inflection point, other areas will begin to look more favorable and a deconcentration or dispersion of activity should be observed.

Finally, in parallel with economic development come demographic changes: lower fertility and mortality rates, with downward shifts timed in such a fashion that rapid population growth is observed, followed subsequently by a balance in birth and death rates that leads to stable population sizes (Notestein 1945; Kirk 1996). This relationship between development and demographic change is summarized by the demographic transition theory. Although often criticized, this remains a basic tenet of geography, sociology, demography, and history, to name a few social science disciplines, with numerous studies aiming to establish the validity of the theory for a particular time and place. Along with criticisms that the theory 
may not hold even in retrospect (to say nothing of countries currently developing), is another one very similar to Alonso's: how does the demographic transition accommodate below replacement level fertility? Put another way, how does the theory accommodate very observable population decline occurring in many regions of the world, as opposed to stability or growth?

A few notable points stand out from the whirlwind tour of development processes outlined above. First, of course, they are all interconnected and to understand one facet of development is to need to consider others. This is an important argument in Alonso's paper. Also, each process, if imagined as a bell curve, necessarily suggests the existence of an inflection point- that is, there is some point at which things change. This does not necessitate that the inflection point will be the same for each curve-that geographic concentration of activity and social and spatial inequality, for example, will all start to change at the same point of an area's economic development. It does argue, though, that there is an identifiable inflection point and that what comes after will be different.

\section{The Right-hand Tails of the Bells: Alonso Was Right}

Alonso has a great many things to say about his five bells; it is his prescience in highlighting the value of the "right-hand tails," though, that we focus on here. Where these tails are concerned, better words than Alonso's (1980) are difficult to find: "When the pace of development slows, how much does it slow? Does the process of regional equalization end with all regions equal? ... Does fertility drop to the point exactly at which births balance deaths?" (p. 12). Observations about the future are necessarily predicated upon past experience. In 1980, Alonso foresaw the future through the lens of the tumultuous 1970s and what he perceived as the approaching tails of his five bells; his exact predictions have not all come to be, however overall his points remain valid. Below we assess what the past thirtyfive years have contributed to knowledge where these points are concerned, where Alonso's predictions have proven accurate (or not), and how regional science has contributed to our understanding of each.

\section{Economic Development}

Before 1750 , practically no economic growth took place worldwide. Nevertheless, the assumption of ongoing economic growth, based on Solow's Nobel prize-awarded work of 1956, is widely accepted (Gordon 2012). Recently, the World Bank revised its 2016 global growth forecast down to 2.4 percent. "The move is due to sluggish growth in advanced economies, stubbornly low commodity prices, weak global trade, and diminishing capital flows" (World Bank 2016a, 1). The recent political instabilities and challenges taking place around the world are likely to impose further limitations to economic growth at the world level and in the advanced economies.

Almost a decade before Alonso's presidential address, in 1972, discussion started on "The Limits to Growth" (Meadows et al. 1972). During the period of economic prosperity and stability in the 1990s and early 2000s the debate faded, but the recent economic crises as well as the increasing challenges posed by climate change and political developments revived the interest in the right-hand tails of economic growth. In and of itself, limited 
economic growth could present less of a challenge than does growth's interaction with other topics. The relationship between economic growth and scarcity of resources (e.g., land, oil, clean air, and clean water) is important, for example. Technological advances are supposed to "decouple" gross domestic product (GDP) growth from "material throughput," but other than for energy this development cannot be found (Jackson 2011). A drawback of many technological advances is however the decoupling of production from labor input. Only when demand increases can the same number of jobs be sustained. Theoretically, economic growth is necessary to prevent and/or reduce poverty (see also World Bank 2016a). The recent economic crisis, however, led to the realization that eternal growth can be questioned. This is also the focus of the recent debate on "secular stagnation," where researchers have emphasized the importance and drawbacks of negative interest rates as the traditional and perhaps only tool left to link saving and investment in order to go back to full employment (Summers 2014).

\section{Social Inequality}

Indeed, the second bell, "predicts" lower social inequality after a certain level of "advanced" economic development. This bell is perhaps the most idealistic one and in fact the economic growth models on which it is predicated are now widely questioned (Barca, McCann, and Rodríguez-Pose 2012). Unfortunately, according to Milanovic (2012), the global level of inequality in terms of purchasing power did not improve between 1980 and 2005. Also, Deininger and Squire (1996) do not find the expected causal relationship between growth and changes in aggregate inequality. Although average income levels between countries might have become more equal, inequality within certain countries has increased. This holds in particular for China ${ }^{2}$ but also for countries such as Germany and Sweden (Organization for Economic Cooperation and Development 2011). Oxfam (Hardoon, Fuentes-Nieva, and Ayele 2016, 1) reported even that " 62 people own as much as the poorest half of the world's population." On a more positive side, there is evidence of a positive relationship between economic growth and the reduction in poverty (Deininger and Squire 1996).

\section{Regional Inequality}

This increasing intracountry inequality also implies larger regional inequalities. In Britain, GDP per person in the richest region in 2011 was five times more than the national average and almost ten times more than the income of residents of the poorest area (Economist 2011). Williamson (1965), who was one of the first to study regional inequalities, concluded that American regions converged between the 1950s and 1960s. However, Amos (1988) determined that between 1969 and 1983 regional inequality had increased again. Thus, he concluded that regional inequality is likely to follow an increase-decrease-increase pattern, contrary to a simple U form or bell form. More recently, Artelaris and Petrakos (2016) confirm this pattern for the European Union 27. In the United States, the famous manufacturing belt is a good example of such regional dynamics. Regional economic development was enormous in the 1960s, partly thanks to car manufacturing activities. Initially, this resulted in strong income inequalities, both within- and between-neighboring

\footnotetext{
${ }^{2}$ Nevertheless, in the case of China (and to a lesser extent India), the increase in inequality does go hand in hand with a sharp reduction in poverty (Ferreira and Ravallion 2008).
} 
regions. However, in the next phase, manufacturing jobs drew many labor migrants to the area, resulting in a diffusion of effects over secondary (residential) cities. The late twentieth century brought back increased regional inequalities, mainly because of the departure of capital to low-wage countries (Fan and Casseti 1994), resulting in a reversed inequality with low incomes in the main cities such as Detroit. Certainly, both regional and social inequality appear to be here to stay for the longer term.

\section{Regional Concentration}

The concept of strong - mostly positive-synergies among clustered economic activities appeals to both researchers and policy makers. Regional concentration, and in particular agglomeration effects, remains among the favorite topics of regional scientists. Urbanization is one of the strongest spatial trends of the last few decades. The world not only reached a milestone in 2007, when more than half of the population lived in urban areas, but the share of people living in settlements with over one million inhabitants also increased steadily to over 22 percent in 2014 (World Bank 2016b). However, in most developed countries, such as Europe and the United States, population concentration has seemed to stabilize at 75-80 percent urban. Whether we can still reasonably expect a decrease in urbanization is an interesting question. We do see shrinking cities in all parts of the world, including the United States and Europe. The Urban Audit of the European Union shows that "out of 220 large and medium-sized European cities, 57 percent of the cities and 54 percent of the larger urban zones lost population in the period from 1996 to 2001" (Wiechmann and Pallagst 2012, 264). At the same time, in particular in Europe, with its polycentric urban structure, higher growth rates of smaller centers take place (Dijkstra, Garcilazo, and McCann 2013).

Nevertheless, there remains a strong policy emphasis on productivity improvements in large agglomerations (Scott and Storper 2007). In addition, the discussion on efficiency versus equity has intensified, as isolated policies that aim to enforce agglomerations often results in larger (regional) income disparities (Scott and Storper 2007).

\section{Demographic Transition}

We all know that fertility rates did not stabilize at the replacement level as Alonso expected or hoped for. Although rapid population growth has halted for most developed countries, what has in fact been observed in many is a slow shift toward population shrinkage-a surfeit of deaths over births that is occasionally only partially mediated by positive net international immigration flows. In Europe in the year 2000, the "negative momentum" started: a tendency of declining population, particular in the younger cohorts, due to lowered fertility rates (Lutz, O'Neill, and Scherbov 2003). Next to this, longer life expectancies result both in developed and in developing countries in aging populations. Although decline and aging often share a common cause in low birth rates, there is no causality between them (Coleman and Rowthorn 2011). Another important demographic change is the changing household composition: average household size has decreased considerably in many parts of the world. Over the last four decades, in the Netherlands average household size decreased from 2.95 to 2.19 and in the United States from 2.94 to 2.54. This means that population decline in many places is accompanied by an increase in the number of households (Coleman and Rowthorn 2011), potentially obscuring the eventual impacts of decline on housing and labor markets. 


\section{Right-hand Regional Science}

Although all five of Alonso's bells underpin regional science knowledge, three are explicitly spatial and have generated more interest on the part of regional researchers: the path of development in general, spatial inequality, and geographic concentration. Each of these three curves calls upon the particular strengths of regional science, requiring the use of spatially disaggregated data and the tools and methods to work with them, the development of spatially explicit theories or understanding of spatial processes, and the ability to synthesize information from a range of disciplines. A consideration of any regional science compilation (e.g., Florax and Plane 2004 or Fischer and Nijkamp 2014) highlights the focus regional scientists have devoted to research areas related to these three bells. Concepts such as clusters, spatial mismatch, or agglomeration provide insight about geographical concentration as well as spatial inequality, while research on networks, transportation, and spatial interaction are all predicated on the existence of a set of areas that are somehow codependent-and often unequal. Innovation and diffusion models, as well as input-output methods, also reinforce connectivity across entities as well as regions. And virtually all regional science methods, especially spatial econometrics and spatial analytic tools in general, are honed on the whetstone of regional growth models or models of regional economic convergence. That is to say, the methods may not have been originally predicated on urban or regional economic growth models, but within regional science, these are the methods frequently brought to bear to test growth hypotheses (e.g., see Rey and Montouri 1999; Dur-anton and Puga 2004; or Rey and Janikas 2005).

The strengths of the discipline have helped carry it up the assorted curves of left-hand regional science. Theories and methods applied to regional growth and convergence, regional income inequality, innovation diffusion, and migration have all helped to explain how and where growth occurs and how regions interact with each other within a context of growth. In addition, the rich methods of regional science and expertise developed regarding spatial units and scale mean that the field is almost uniquely positioned to contribute to a "right-hand" world, one in which lack of growth, shrinkage, or increased inequality (whether social or spatial) appears more frequently. In this context, solid policy development, new theoretical perspectives, and improved methodological tools all require an understanding of how a new world order (or at least regional order) may be emerging.

A key strength of regional science is the tool kit of methods and models that have been finetuned over decades of regional research (for the case of input-output modeling, see Batey 2016). Although an enormous range of methods exists within the field, two common elements emerge. First, because regional science is by nature regional, virtually any regional science application requires determination of the appropriate spatial unit, an understanding of the impact that choice of units may have on results (i.e., the modifiable areal unit problem, Openshaw and Taylor 1979), and preferably some connection between choice of unit and the spatial process under investigation. Size of units, characteristics of units, and the configuration thereof are all already important for the so-called left-hand regional science. An open question is how-as patterns of geographic concentration or spatial inequality change, for example - choice of units might serve to expose or hide emerging trends and regularities that run contrary to received knowledge. Existing research rests on expectations 
of spatial spillovers and interactions across spatial scales. Not only may these expectations change in the future, but it will require regional researchers to be aware of the shifts.

In addition, the issue of nonlinearity is highly relevant. A classical transport-economics example explains how just a few extra cars on the road might cause the rest to be delayed. This implies that the marginal effect of an additional car strongly depends on the total number of cars that are present. Intuitively, a small reduction in cars might have an outsized positive effect on many other users/stakeholders in a region - but the magnitude of these effects in an environment of decline or stagnation is unknown. In the case of people, research tends to focus on the impact of additional people; how, when, and where losses of people might be felt is unknown. The transport example furthermore suggests that the effect of decline might not be felt or visible in the same localities where the depopulation takes place (Spencer 1997).

Time is a fundamental aspect of Alonso's description as well. Development may be the underlying theme, but time governs the path toward inflection point, its timing, and also the trend that follows on the right side. Regional spatial inequality may increase to a certain point before decreasing (or shifting up a gear to a higher level, as certainly seems possible), but the timescale governing the process determines whether this happens over years, decades, or centuries. When the timescale gets larger, focusing on path dependency becomes important (see Martin and Sunley 2006).

Another common thread running through most regional science methods or guiding principles is the simultaneous consideration of multiple contributors to regional change. A region may grow and this will depend to some extent on its location, neighbors, and larger spatial context. It will also depend on demographic and economic factors and the interplay between these. Migration research within a regional science context, for example, generally addresses migrant characteristics but also the characteristics of origins and destinations. Regional concentration, whether of people or economic activity, requires not only consideration of the spatial aspects suggested above but also an understanding of the interplay between people, location, and economy. Regional science excels at this.

Consider for example Alonso's social and spatial inequality bells. Each is treated individually in Alonso's description (although another fundamental argument he makes is that interactions across curves are important to study), even though some of the more interesting aspects of each have to do with their potential interactions. A fertile avenue of research in the social sciences has been the spatial manifestation of social inequality; that is, that societies may be unequal in distribution of income and this uneven distribution also plays out in space. Research on residential segregation, for example, is just one example of this interaction. Now suppose we consider changes in the interaction between social and spatial inequality that might occur in a larger context of economic/demographic stagnation or decline. Certainly, in a world where economic growth has slowed, some regions will continue to outperform others, even if at a lower level. This in turn affects social inequality; as noted above, all current signs point to entrenched income inequality, even in a larger environment of growth. Should the rate of development slow, or become negative, surely social inequality will suffer. It also seems likely that this will lead to increased spatial 
inequality (at multiple spatial scales, from local to regional to global) and that people and economic activity will become further concentrated.

\section{Case Study: Population Decline}

Periods of population decline have been numerous throughout the history of humankind. However, this was mostly caused by increases in death rates through famine, epidemics, or war. In such high-mortality populations, simple improvements in survival through nutrition and hygiene quickly resulted in growing and younger populations. Today, we face decline that is largely related to a lowering of fertility rates below the replacement level of 2.1 children per women. In areas where natural growth rates are close to zero, population decline is also the result of outmigration (Franklin 2014). Many examples at the urban level in developed countries show how a difficult economic climate in terms of, for example, employment initiates a process of selective out-migration (Friedrichs 1993). In addition, although we emphasize demographic aspects of decline, loss of population is inextricably tied to forces operating at multiple spatial scales. Decline is thus inherently spatial.

Measures and impacts of decline vary across spatial scales (or should: little research exists to examine this hypothesis). Understanding of decline requires conceptual and analytical tools that allow space and time to be considered simultaneously.

\section{Economic Development and Decline}

What is it exactly we are afraid of? It is generally assumed that a declining population implies lower demand and hence slower output growth, unless it is compensated for by new production technologies. This heavily depends on the assumption of similar preferences of current and future consumers and thus of similar consumption behavior (van Dalen and Henkens 2011). However, so far, no proof has been found of a positive relationship between population size and GDP per head or between the growth rates of these variables (Coleman and Rowthorn 2011). Nor has population decline in developed countries led to economic decline per capita so far. However, at the regional level, these relationships might actually exist. An interesting study conducted in the Netherlands shows that people are well aware of "the potential economic disadvantages of population decline," but that they also anticipate and appreciate the potential intangible advantages (van Dalen and Henkens 2011).

\section{Social Inequality}

"The prospect of population decline can be of considerable importance for an extensive welfare state" (van Dalen and Henkens 2011, 444). In particular in the so-called pay-as-yougo pension systems, the payments will exceed the contributions. Countries (and regions) with aging populations will face an even less sustainable financial basis. This financial basis is likely to be threatened when government expenditures are fixed or slow to adjust (Brunner 1996). In addition, important challenges appear when population levels drop below thresholds that are needed to finance indispensable public facilities (e.g., schools, hospitals, public transport; van Dalen and Henkens 2011; see also Feser and Sweeney 2003). Here, a complex challenge arises not only of funding public facilities and infrastructure with decreasing resources but also of maintaining some minimum level of service provision that, in the face of declining population densities, increases in cost. Raising taxes for the ones 
who stay behind will either increase out-migration or increase social inequality when certain groups of people do not have the resources to leave.

\section{Regional Inequality}

In certain areas, decline might result in less unemployment and higher wages, resulting in more equity in terms of regional income. However, when firms decide to leave or have to close due to a declining number of customers, this positive development will halt. A lower level of regional income will affect expenditures on all types of goods as well as on houses. When an area becomes less popular for whatever reason, the prices of houses might drop. For young people who have yet to enter the housing market, this may be good news, but for homeowners, the consequences of population decline might be disastrous (van Dalen and Henkens 2011). In particular, households with a long-term mortgage based on the original, higher housing price can be locked into a situation where they have no choice but to "vote with their feet" anymore. This will increase regional inequality in terms of income and age structure as well as in terms of public finances.

\section{Geographic Concentration}

An important element of the debate on decline is that the geographical perspective matters. Regional and urban decline are in most countries accompanied by growth in other regions or cities (Coleman and Rowthorn 2011, van Leeuwen 2015). As with growth, decline should not be expected to be evenly spread over society or over space. This is likely to increase social and regional inequality. Often it is thought that decline mainly hits rural regions. However, when taking into account Europe as a whole, it appears that the share of people potentially affected by population decline in rural and urban regions is very similar (European Union 2010). Instead, it is the intermediate regions that most frequently face population decline. ${ }^{3}$

Shrinkage in urban areas mostly takes place in "structurally weak areas such as old industrialized rust belts or in towns on the periphery of the urban system" (Wiechmann and Pallagst 2012, 262). Such economic decline can be caused by the loss of the relative economic position of a city in a wider market, for example, because of the maturation of an important sector within the urban economy (Markusen 1985). Rural decline is mostly observed in the least accessible regions. Here, a lack of jobs and opportunities often pushes people out (Andersen and van Kempen 2003; Guimarães et al. 2016). The accessible rural areas on the other hand often seem to gain population, since they are places with high levels of amenities and good access to urban services. Overall, these developments suggest lower regional concentrations but a stronger divide between accessible and inaccessible areas.

While both growth and decline at the local level might result from coinciding unexpected and unrelated events (large firms that decide to locate or leave, incapable politicians, local birth or death booms), decline at the regional level could indicate more structural issues. When local governments, for example, try to prevent future decline and start a "race to the bottom" by trying to attract people or businesses from other regions or countries, this can

\footnotetext{
${ }^{3}$ As well as the highest share of population among the three types of regions.
} 
clearly result in a situation where improving the situation in one region impairs the problems of a neighboring one (van Dalen and Henkens 2011). Studying the links between spatial spillovers, income convergence, and inequality is of utmost importance (Rey and Janikas 2005). This should not only be done at the regional, macro level but also at the local or even individual, micro level, in order to better understand causalities between important dynamics.

\section{Demographic Transition}

To understand the economic effect of decline, it is important to understand what happens to the population structure. The effect of decline caused by the migration of skilled workers or decreasing fertility rates will be very different. This is mainly due to the different population dependency ratios and their effects on productivity levels. Regions with more job opportunities are known to be more appealing in particular to the young adult population (Arnott and Chaves 2012; Lutz 2001). Because youth are less attached to their city of residence, they are therefore more likely to leave shrinking regions compared to the older, more established residents (Zimmermann 2005). City councils' fears of declining communities are therefore understandable. When firms or households leave a specific region, this may hint to other entrepreneurs and citizens that an area is at the forefront of a period of economic stagnation or decline (van Dalen and Henkens 2011).

In rural areas, population decline can be caused by both out- and in-migration. Outmigration can be caused by a lack of employment opportunities. However, certain areas are very much appreciated by high(er)-income middle-aged and elderly who appreciate the countryside. Even though such well-off households might be good for the local economy, when they replace indigenous, larger families, a net loss of population can occur (Spencer 1997). In particular, in very attractive areas, this can result in a paradox of a high residential demand accompanied by depopulation when not enough new houses are built to offset falling average household size (Spencer 1997).

\section{Less Is More?}

A change of mind-set is one of the most important developments that need to take place to be able to deal with—and perhaps even take advantage of — population decline. Although politicians already use provocative slogans such as "less is more" or "opportunities through decline," decline still has a negative connotation. However, why would planning for decline be more difficult than planning for growth? Is it that costs of congestion and pollution are generally neglected, because it is natural to focus on growth? Costs of congestion and crowding will decline with smaller populations. In certain areas, this will result in lower journey to work times, less traffic, and fewer related accidents (Coleman and Rowthorn 2011). In addition, emissions and pollution of all kinds are likely to fall with benefits for human health (Costello et al. 2009). Moreover, certain areas will benefit from more space and opportunities for natural areas. The advantages of more physical space and greater flexibility in land use can be seen in Japan (Coulmas and Lützeler 2011) but also in the Netherlands. Place attachment might be the key to encouraging residents to participate in local strategies and initiatives to make "shrinkage an opportunity rather than a threat" (Guimarães et al. 2016, 1704; Hospers 2013). 


\section{Conclusion: Challenges for Regional Science}

Alonso's presidential address and his taxonomy of development "bells" provide one lens through which to characterize humankind's progress through various development states. A strength of Alonso's approach, we believe, is his conceptualization of development processes as bell shapes that necessarily possess pre- and post-inflection point identities. Regional science, social science, and quite possibly human nature, as well, tend to judge progress and development in terms of growth. Alonso's framework allows for identical processes to operate under different regimes or paradigms (both growth and decline), and this in turn has implications for the theories and methods underpinning most existing regional science research. This article has brought Alonso's five bells into the twenty-first century and has attempted to address some of the implications of his arguments for our field. Below we lay out a few thoughts on a potential research roadmap for a right-hand regional science, emphasizing especially the ways in which the discipline could contribute to the study of population decline.

First, deciding on the appropriate spatial scale is a very important but often underrated research step. The "relevant" space (and time period) should be defined by the spatial processes under study, such as migration and commuting patterns, the diffusion of ideas and information, or the development of entrepreneurial activities (Meentemeyer 1989). Consequently, it is important to realize that the relevance and significance of factors often differ at different spatial levels. Studying interactions across spatial processes and the inherently different spatial scales calls for theoretical innovations. Second, when focusing on regional differences, it is important to take a multidimensional focus. When looking at "living standards," for example, it is not always meaningful to compare absolute values or even certain relative ones. Average values can hide important underlying structural patterns of inequality. But more importantly, they often lack insight in composition effects. A declining region might have a relatively low average income not due to negative externalities but because of the type of jobs present.

Along these lines, we see two particular arenas where regional scientists could help develop new knowledge. The first is theoretical: what does what we have learned so far about regional configuration, interaction, and dependence suggest for post-inflection point portions of Alonso's curves, assuming these inflection points exist and are identifiable? The second is topical: in regional science, as in other social sciences, issues surrounding quality of life, economic development, or transportation rest on assumptions of growth, or at least the assumption that the best predictors of the future are what has occurred in the past. How can we begin to speculate about the range of future possibilities, given what we know? Building on both the theoretical and the topical, we have here provided a case study-population decline - that exemplifies much of what Alonso alludes to in his piece and highlights the dearth of current thinking on the subject in regional science as well as how the issue is so clearly one that falls within the purview of the discipline.

We close by noting that, although post-inflection point research on Alonso's five bells begs for theoretical and topical contributions, some of the key challenges are purely practical. Will existing measures and definitions capture or obscure major shifts in development 
curves, such as geographical concentration or regional inequality? Where population loss is concerned, can we define thresholds of certain variables after which decline becomes a real problem - for example, thresholds in the total number of people within a community, or the number of public facilities, of the level of diversity (in terms of age, cultural background, income)? Population decline involves an absence of something; how do we study the people who are no longer in a location? Here, too, there are fruitful avenues of research to be pursued.

\section{Acknowledgments}

\section{Funding}

The author(s) disclosed receipt of the following financial support for the research, authorship, and/or publication of this article: Franklin's contribution to this article was supported by the Eunice Kennedy Shriver National Institute of Child Health and Human Development of the National Institutes of Health under award number R03HD083518.

\section{References}

Alonso W. Five Bell Shapes in Development. Papers of the Regional Science Association. 1980; 45:516.

Amos OM. Unbalanced Regional Growth and Regional Income Inequality in the Latter Stages of Development. Regional Science and Urban Economics. 1988; 18:549-66.

Andersen HT, van Kempen R. New Trends in Urban Policies in Europe: Evidence from the Netherlands and Denmark. Cities. 2003; 20:77-86.

Arnott RD, Chaves DB. Demographic Changes, Financial Markets, and the Economy. Financial Analysis Journal. 2012; 68:23-46.

Artelaris P, Petrakos G. Intraregional Spatial Inequalities and Regional Income Level in the European Union Beyond the Inverted-U Hypothesis. International Regional Science Review. 2016; 39:291317.

Barca F, McCann P, Rodríguez-Pose A. The Case for Regional Development Intervention: Place-based Versus Place-neutral Approaches. Journal of Regional Science. 2012; 52:134-52. DOI: 10.1111/j. 1467-9787.2011.00756.x

Batey WJ. What Can Demographic-Economic Modeling Tell Us about the Consequences of Regional Decline? International Regional Science Review. 2016; doi: 10.1177/0160017616654741

Blank R. Poverty, Policy, and Place: How Poverty and Policies to Alleviate Poverty Are Shaped by Local Characteristics. International Regional Science Review. 2005; 28:441-64.

Brunner JK. Transition from a Pay-as-you-go to a Fully Funded Pension System: The Case of Differing Individuals and Intragenerational Fairness. Journal of Public Economics. 1996; 60:13146.

Coleman D, Rowthorn R. Who's Afraid of Population Decline? A Critical Examination of Its Consequences. Population and Development Review. 2011; 37:217-48. [PubMed: 21280372]

Costello A, Abbas M, Allen A, Ball S, Bell S, Bellamy R, Friel S, Groce N, Johnson A, Kett M, Lee M. Managing the Health Effects of Climate Change. The Lancet. 2009; 373:1693-733.

Coulmas, F., Lützeler, R., editors. Imploding Populations in Japan and Germany: A comparison. Vol. 25. the Netherlands: Brill; 2011.

Deininger K, Squire L. A New Data Set Measuring Income Inequality. The World Bank Economic Review. 1996; 10:565-91.

Dijkstra L, Garcilazo E, McCann P. The Economic Performance of European Cities and City Regions: Myths and Realities. European. Planning Studies. 2013; 21:334-54.

Duranton G, Puga D. Micro-foundations of Urban Agglomeration Economies. Handbook of Regional and Urban Economics. 2004; 4:2063-117.

Economist. [Accessed October 14, 2016] Regional Inequality, Divided We Stand. 2011 Mar 11. http:// www.economist.com/blogs/dailychart/2011/03/regional_inequality 
European Union. Eurostat Regional Yearbook 2010. Belgium: Eurostat Statistical Books; 2010. http:// ec.europa.eu/eurostat/statistics-explained/index.php/Rural_development_statistics_by_urbanrural_typology [Accessed October 14, 2016]

Fan CC, Casetti E. The Spatial and Temporal Dynamics of US Regional Income Inequality, 19501989. The Annals of Regional Science. 1994; 28:177-96.

Ferreira, FH., Ravallion, M. Global Poverty and Inequality: A Review of the Evidence. World Bank Policy Research Working Paper Series 4623. Washington, DC: The World Bank; 2008.

Feser E, Sweeney S. Out-migration, Depopulation, and the Geography of US Economic Distress. International Regional Science Review. 2003; 26:38-67.

Fischer, MM., Nijkamp, P., editors. Handbook of Regional Science. Heidelberg, Germany: Springer; 2014.

Florax RJ, Plane DA. The Brightest of Dawns: 50 Years of Regional Science, Golden Anniversary Issue of Papers in Regional Science. Papers in Regional Science. 2004; 83:6-29.

Franklin, RS. The Landscape of Population Decline in the United States: Considering the Roles of the Demographic Components of Change and Geography. In: Richardson Harry, W., Nam, Chang Woon, editors. Shrinking Cities: A Global Perspective. London, UK: Routledge; 2014. p. 75-85.

Friedrichs J. A Theory of Urban Decline: Economy, Demography and Political Elites. Urban Studies. 1993; 30:907-17.

Gordon, RJ. Is US Economic Growth Over? Faltering Innovation Confronts the Six Headwinds. NBER Working Paper 18315. Cambridge: National Bureau of Economic Research; 2012.

Guimarães MH, Nunes LC, Barreira AP, Panagopoulos T. What Makes People Stay in or Leave Shrinking Cities? An Empirical Study from Portugal. European Planning Studies. 2016; 24:1-25.

Hardoon, D., Fuentes-Nieva, R., Ayele, S. An Economy for the 1\%: How Privilege and Power in the Economy Drive Extreme Inequality and How This Can Be Stopped. Oxford, UK: Oxfam International; 2016.

Hospers GJ. Coping with Shrinkage in Europe's Cities and Towns. Urban Design International. 2013; 18:78-89.

Jackson, T. Prosperity without Growth: Economics for a Finite Planet. Washington, DC: Earthscan; 2011.

Keynes JM. Some Economic Consequences of a Declining Population. Eugenics Review. 1937; 29:1317. [PubMed: 21260258]

Kirk D. Demographic Transition Theory. Population Studies. 1996; 50:361-87. [PubMed: 11618374]

Kuznets S. Economic Growth and Income Inequality. The American Economic Review. 1955; 45:128.

Lutz JM. Determinants of Population Growth in Urban Centres in the Republic of Ireland. Urban Studies. 2001; 38:1329-40.

Lutz W, O’Neill BC, Scherbov S. Europe's Population at a Turning Point. Science. 2003; 299:199192. [PubMed: 12663901]

Markusen, AR. Profit Cycles, Oligopoly and Regional Development. Cambridge, MA: MIT Press; 1985.

Martin R, Sunley P. Path Dependence and Regional Economic Evolution. Journal of Economic Geography. 2006; 6:395-437.

Meadows, DH., Meadows, DL., Randers, J., Behrens, WW. The Limits to Growth. New York: Potomac Meadows; 1972.

Meentemeyer V. Geographical Perspectives of Space, Time, and Scale. Landscape Ecology. 1989; 3:163-73.

Milanovic B. Global Inequality Recalculated and Updated: The Effect of New PPP Estimates on Global Inequality and 2005 Estimates. The Journal of Economic Inequality. 2012; 10:1-18.

Notestein, Frank W. Population: The long view. In: Schultz, TW., editor. Food for the World. Chicago: University of Chicago Press; 1945. p. 36-57.

Organization for Economic Cooperation and Development. Divided We Stand, Why Inequality Keeps Rising. Paris, France: Organization for Economic Cooperation and Development; 2011. 
Openshaw S, Taylor PJ. A Million or So Correlation Coefficients: Three Experiments on the Modifiable Areal Unit Problem. Statistical Applications in the Spatial Sciences. 1979; 21:127-44.

Rey SJ, Montouri BD. US Regional Income Convergence: A Spatial Econometric Perspective. Regional Studies. 1999; 33:143-56.

Rey SJ, Janikas MV. Regional Convergence, Inequality, and Space. Journal of Economic Geography. 2005; 5:155-76.

Rostow WW. The Stages of Economic Growth. The Economic History Review. 1959; 12:1-16.

Scott AJ, Storper M. Regions, Globalization, Development. Regional Studies. 2007; 37:579-93.

Solow RM. A Contribution to the Theory of Economic Growth. The Quarterly Journal of Economics. 1956; 70:65-94.

Spencer D. Counterurbanisation and Rural Depopulation Revisited: Landowners, Planners and the Rural Development Process. Journal of Rural Studies. 1997; 13:75-92. [PubMed: 12348273]

Summers, LH. Reflections on the 'New Secular Stagnation Hypothesis. In: Baldwin, R., Teulings, C., editors. Secular Stagnation: Facts, Causes and Cures. London, UK: Centre for Economic Policy Research; 2014. p. 27-40.

van Dalen HP, Henkens CJIM. Who Fears and Who Welcomes Population Decline? Demographic Research. 2011; 25:437-464.

van Leeuwen ES. Urban-rural Synergies: An Explorative Study at the NUTS3 Level. Applied Spatial Analysis and Policy. 2015; 8:273-89.

Wiechmann T, Pallagst KM. Urban Shrinkage in Germany and the USA: A Comparison of Transformation Patterns and Local Strategies. International Journal of Urban and Regional Research. 2012; 36:261-80. [PubMed: 22518884]

Williamson JG. Regional Inequality and the Process of National Development: A Description of the Patterns. Economic Development and Cultural Change. 1965; 13:1-84.

World Bank. Global Economic Prospects, Divergence and Risks. Washington, DC: The World Bank; 2016 .

World Bank. [Accessed October 14, 2016] World Development Indicators. 2016b. http:// wdi.worldbank.org/table/3.12\#

Zimmermann KF. European Labour Mobility: Challenges and Potentials. De Economist. 2005; 153:425-50. 